\title{
Eco-friendly indigo reduction using bokbunja (Rubus coreanus Miq.) sludge
}

\author{
Younsook Shin ${ }^{1 *}$, Min Choi ${ }^{1}$ and Dong $\|$ Yoo $^{2}$
}

\author{
* Correspondence: \\ yshin@chonnam.ac.kr \\ ${ }^{1}$ Department of Clothing and \\ Textiles/Human Ecology Research \\ Institute, Chonnam National \\ University, Gwangju, Korea \\ Full list of author information is \\ available at the end of the article
}

\begin{abstract}
The utilization of Bokbunja (Rubus coreanus) sludge as a source of reductant was investigated to develop an eco-friendly indigo dyeing process. Total sugar contents were 18.94 and $50.87 \%$ for ethanol and water extracts, respectively. The extract was effective to reduce indigo dye. Reduction of indigo was occured rapidly in the solution containing the extract and indigo dye in alkaline condition and it reached to the maximum color yield in one or two day. The reduction potential of the extract was stabilized between $-550 \mathrm{mV}$ and $-600 \mathrm{mV}$ depending on concentration of the extract. At higher concentration of the extract, reduction power was maintained stably for longer time and stronger color yield. It was confirmed that the Bokbunja sludge extract can be an eco-friendly and safe alternative to sodium dithionite as a reducing agent in indigo dyeing processes.
\end{abstract}

Keywords: Bokbunja (Rubus coreanus) sludge; Reductant; Indigo dyeing; Reduction potential; Color yield

\section{Introduction}

Bokbunja (Rubus coreanus Miq.) is a kind of wild berry in the family Rosaceae. Its growth is limited to the south-east Asian countries including southern parts of the Korea, China and Japan (Choi et al. 2006). Bokbunja was mainly used to produce traditional wine and has also recently been used in manufacturing jellies, jams, juices, and beverages. Also, a variety of health-promoting products are being developed. The increase in Bokbunja consumption is also leading to the generation of vast quantities of wastes. Bokbunja sludge is generated about $20 \%$ on the weight of fruits in processing and contains large amount of effective components such as anthocyans, sugars, and phenolics. It is used as animal feed and compost, however additional cost for its disposal is needed. Bokbunja fruit contains phenolic acids, organic acids, sugars such as glucose, fructose, sucrose, pectin, flavonoids, gallotannin and ellagitannin, etc. (Yoon et al. 2003). A previous study conducted to evaluate Bokbunja wastes (Ku and Mun, 2008) revealed that hot water extracts of Bokbunja pulp were primarily composed of free and combined organic acids (6.9\% and $8.9 \%$, respectively), sugars $(69.9 \%)$, pectin (19.1\%), and anthocyanin (5.2\%). We became interested in the utilization of Bokbunja sludge because it contains a large percentage of sugar and antioxidative components. Sugars such as glucose, fructose and sucrose contained in Bokbunja sludge has been used for the reduction of indigo and sulfur dyes (Meksi et al. 2012; Blackburn \& Harvey, 2004). Whereas, Bokbunja is an important source of anthocyanins, which are 
phenolics and of great nutritional interest due to their antioxidant, antineoplastic, antiinflammatory, anticarcinogenic, antiviral, and antibacterial properties (Peschel et al., 2006; Vareed et al. 2006). Antioxidants from residual sources could be used to increase the stability of foods by preventing lipid oxidation and to protect against oxidative damage in living systems by scavenging reactive oxygen species (Moure et al., 2001). Therefore, antioxidative components in Bokbunja wastes could contribute to enhance the stability of reduced form of indigo (leuco-indigo) by preventing oxidation. Thus, this study was conducted to evaluate the use of the Bokbunja sludge extract as reducing agent in indigo dyeing. Hardly any work has been done on the utilization of bokbunja sludge extract in indigo reduction. New application of Bokbunja sludge is of significant interest especially due to the increase in Bokbunja comsumption in Korea. Obviously, the utilization of wastes would contribute to maximizing the available resources and would contribute to solving waste disposal problems.

The indigo dye is insoluble in water and cannot be used for dyeing without reducing. So, the reduction of indigo to leuco-indigo represents a critical wet process in textile industry, which is operated worldwide on a large scale for the dyeing of denim and blue jean products. In most industrial indigo dyeing process, sodium dithionite is used mainly due to powerful reduction of indigo. However, it generates non-regenerable oxidation products and causes various problems in the disposal of the dyebath and the washing water. After several decades of research and development there is still no commercial reducing technology available today that can replace sodium dithionite in all areas of vat dye applications. There have been previous attempts to replace sodium dithionite as reducing agents for dyeing with vat dyes wholly or partly by reducing sugars such as glucose (Meksi et al. 2012), fructose, lactose, galactose and maltose (Blackburn and Harvey, 2004).

The aim of this study is to investigate the utilization of Bokbunja sludge extract as a natural organic reducing agent for indigo dyeing. Extraction was carried out using water and ethanol and their effectiveness was compared in terms of yield, total sugar content, and antioxidant activity to determine better extraction medium. The reducing power of the water extract of Bokbunja sludge was evaluated by measuring reduction potential and color yield.

\section{Methods}

\section{Materials}

Bokbunja sludge was provided by Bokbunja Wine Company, Gochang, Korea. It was stored in a refrigerator. Synthetic indigo (Sigma) and 100\% ramie fabric (density; $60 \times 46 / \mathrm{in}^{2}$, weight; $118 \mathrm{~g} / \mathrm{m}^{2}$, thickness; $0.32 \mathrm{~mm}$ ) were purchased commercially. All the chemicals and reagents were of analytical grade.

\section{Extraction of bokbunja sludge}

Dried Bokbunja sludge samples (50 g) were added to an Erlenmeyer flask with $1 \mathrm{~L}$ distilled water and then refluxed at $100^{\circ} \mathrm{C}$ for $60 \mathrm{~min}$. Extracted solution was filtered, concentrated under vacuum using a rotary evaporator, shock frozen at $-80^{\circ} \mathrm{C}$ and frozendried at $-50^{\circ} \mathrm{C}$ to give a crude extract powder. Ethanol (70\%) extract was carried out at room temperature for $24 \mathrm{~h}$ with agitation using an inverter and thereafter, same procedures with water extract described in above were followed. The crude extract powder was used without purification. 


\section{Total carbohydrate content}

Total carbohydrate analysis was done by a phenol-sulfuric acid method (Masukoa et al. 2005; Saha and Brewer, 1994). Absorbance was measured by UV-vis spectrophotometer at $490 \mathrm{~nm}$, using glucose as a standard sugar.

\section{DPPH radical scavenging activity}

DPPH (1,1-diphenyl-2-picryl-hydrazyl) radical scavenging activity of the aqueous solution of the extract was estimated according to the method of Blois (1958). Extract solution $(0.05 \mathrm{ml})$ at different concentration was added to $0.95 \mathrm{ml}$ of $0.1 \mathrm{mM} \mathrm{DPPH}$ in ethanol. The absorbance of solution was measured after $30 \mathrm{~min}$ at $517 \mathrm{~nm}$ by UV-vis spectrophotometer (Agilant 8453, Agilant Technologies, Waldbronm, Germany). The percentage of DPPH scavenging activity was calculated from the equation

$$
\text { Radical scavenging activity }(\%)=(\text { Ac-As }) / \text { Ac }
$$

where Ac is the absorbance of control sample and As is the absorbance of extract sample.

\section{Reduction process of indigo}

A solution containing $0.5 \mathrm{~g}$ of synthetic indigo, $5 \mathrm{~g}$ of calcium hydroxide and an appropriate amount of the Bokbunja sludge extract powder were prepared by adding them to $150 \mathrm{ml}$ of distilled water. This solution was brought up to $80^{\circ} \mathrm{C}$. Reduction potential was measured at $60^{\circ} \mathrm{C}$ using a Bioanalytical Systems CV-27 Voltammograph (BAS, USA), which incorporated a platinum band electode and an $\mathrm{Ag}-\mathrm{AgCl}$ reference electrode.

\section{Indigo dyeing}

The reaction medium obtained from the reduction process of indigo as previously described was used as a dyebath. Namely, indigo vat of $150 \mathrm{ml}$ was prepared by adding $0.5 \mathrm{~g}$ of indigo, calcium hydroxide $(5 \mathrm{~g}$ ) with varied amount of the water extract powder and temperature of the vat brought up to $80^{\circ} \mathrm{C}$. Fabric was dipped in the indigo vat at $60^{\circ} \mathrm{C}$ for $20 \mathrm{~min}$, followed by exposed in air, and washed in distilled water with soap. After neutralizing in acetic acid solution, dyed samples were rinsed and dried in open air for further evaluation.

\section{Color yield}

The color yield (K/S value) was calculated from the diffuse reflectance of the samples using Kubelka-Munk equation.

$$
\mathrm{K} / \mathrm{S}=(1-\mathrm{R})^{2} / 2 \mathrm{R}
$$

where $\mathrm{R}$ is the reflection of the dyed sample.

The reflectance of the dyed sample was measured at the maximum adsorption wavelength on a Macbeth Coloreye 3100 spectrophotometer. Absorbance of the extract solution was measured using a UV-vis spectrophotometer (Agilant 8453, Agilant Technologies, Waldbronm, Germany). 
Table 1 Extract yield and total sugar of extract powder

\begin{tabular}{lll}
\hline Solvent & Yield (\%) & Total sugar (\%) \\
\hline $\mathrm{EtOH}$ & 7.2 & 18.94 \\
$\mathrm{H}_{2} \mathrm{O}$ & 9.7 & 50.87 \\
\hline
\end{tabular}

\section{Results and discussion}

\section{Total sugar content of bokbunja sludge extract}

Extraction yields were 7.2 and $9.7 \%$ on the weight of dried Bokbunja sludge with ethanol and water, respectively. Total sugar contents of the extract were 18.94 and $50.87 \%$ for ethanol and water extracts, respectively (Table 1). Considering higher yield and sugar content, water was more effective solvent for extracting Bokbunja sludge.

A previous study (Ku and Mun, 2008) revealed that hot water extracts of Bokbunja pulp contained neutral sugars (69.9\%) such as glucose, fructose, and sucrose as well as anthocyanin (5.2\%). Considering total sugar content, it was speculated that the Bokbunja sludge extract prepared in this study also contained reducing sugars and so, it can be used as a reducing agent in indigo dyeing. Reducing sugars have been used for reduction processes as possible benign alternative reducing agents for indigo (Meksi et al., 2012) and sulfur dyes (Blackburn and Harvey, 2004). Their reducing effect is associated with an electron-rich intermediate (Vuorema et al. 2009). Employment of food by-products as a source of reducing sugars has the advantage that harmful environmental effects can be avoided.

DPPH radical scavenging activity of the bokbunja sludge extract

$\mathrm{DPPH}$ radical scavenging activity indicates the ability of inhibiting oxidation of the extract. It is widely used to characterize antioxidant activity of plant material (Arnao, 2000). Anthocyanins in Bokbunja are phenolics, exhibiting antioxidant activity, and their molecules are unstable and highly susceptible to degradation by $\mathrm{pH}$, temperature, light, sugars, etc. (Eiro and Heinonen, 2002).

The DPPH radical scavenging activities of Bokbunja sludge extract are shown in Figure 1. The DPPH radical scavenging activity was concentration-dependent. The highest $\mathrm{DPPH}$ radical scavenging activities were $88.8 \%$ at $2.5 \mu \mathrm{g} / \mathrm{mL}$ of the ethanol extract and

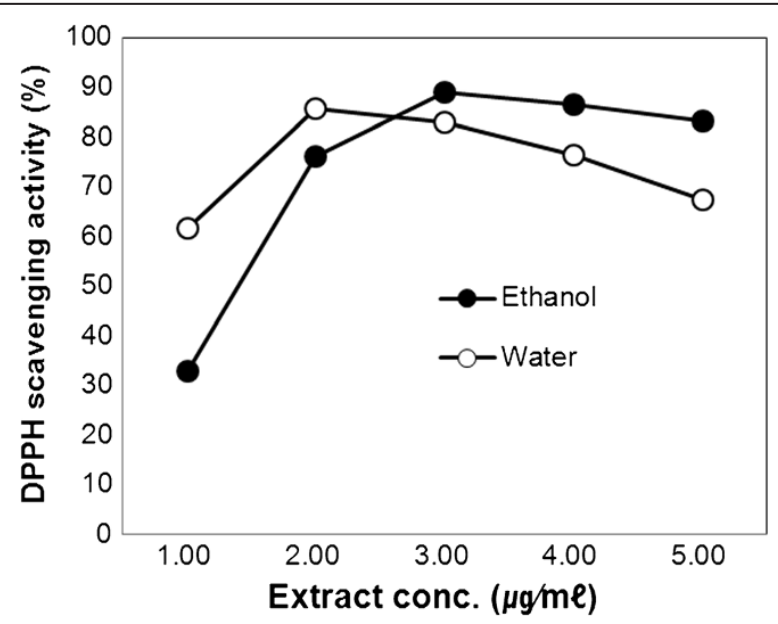

Figure 1 DPPH radical scavenging activity of the Bokbunja sludge extract. 


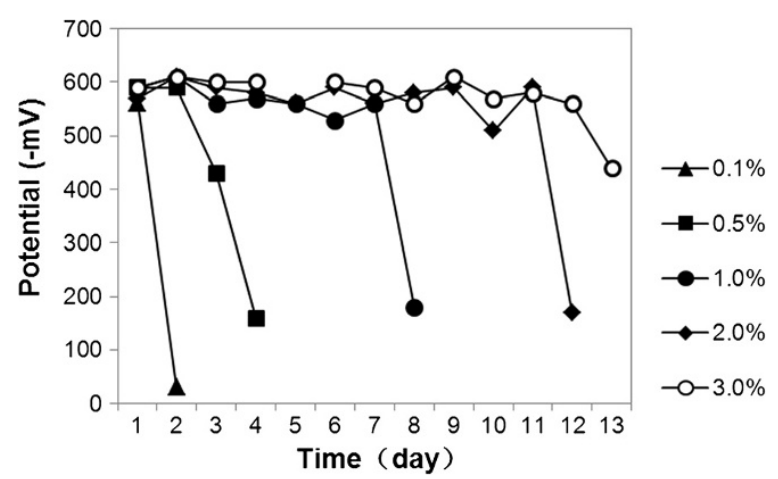

Figure 2 Changes in reduction potential depending on the bokbunja sludge extract concentration.

$85.5 \%$ at $1.5 \mu \mathrm{g} / \mathrm{mL}$ of the water extract, respectively. There were slight differences of scavenging activity depending on the solvent type used for extraction. The water extract showed higher antioxidant activity than the ethanol extract at lower concentration. Whereas, at higher concentration the ethanol extract exhibited higher activity than the water extract. It was presumed that this difference may be caused by the different composition of the extract depending on solvent type. Further study would be needed for elucidating the influence of extraction solvent on the antioxidant activity.

From the results obtained, it was considered that the Bokbunja sludge extracts can be used as a natural antioxidant and the water extract was more effective compared to the ethanol extract. Antioxidant activity of the Bokbunja sludge extract would have a positive effect on the stability of reduction process because it could prevent leuco-indigo from oxidizing to indigo by scavenging reactive oxygen species (Moure et al., 2001).

\section{Reducing power of the bokbunja sludge extract}

Reaction medium was prepared by adding synthetic indigo and the water extract of Bokbunja sludge in a medium containing calcium hydroxide $(5 \mathrm{~g} / 150 \mathrm{ml})$. The reducing power was evaluated by measuring reduction potential of the prepared reaction medium. The evolution of reduction potential at various concentration of the extract was investigated over a period of $2 \sim 14$ days. The obtained results are illustrated in Figure 2. The reduction of indigo was occurred rapidly and reduction potential fell sharply. Reduction potential was stabilized between $-550 \mathrm{mV}$ and $-600 \mathrm{mV}$. The reduction potential remained stably for a certain period time $(1 \sim 13$ days $)$ depending on the extract concentration.

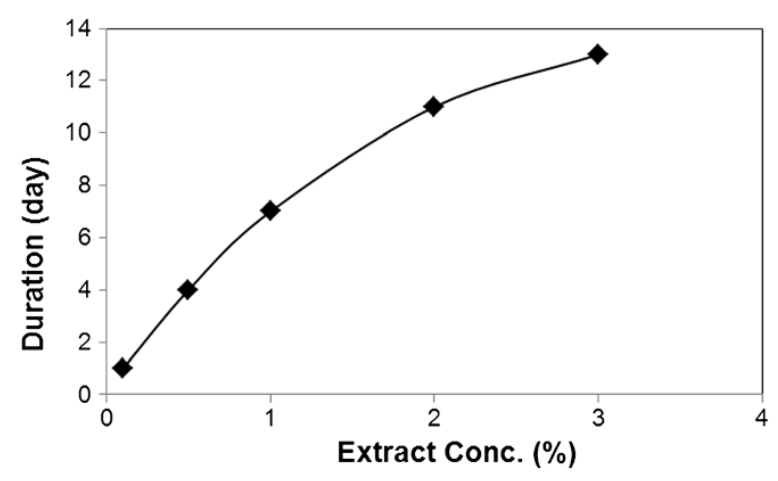

Figure 3 The effect of bokbunja sludge extract concentration on the stability of reduction medium. 


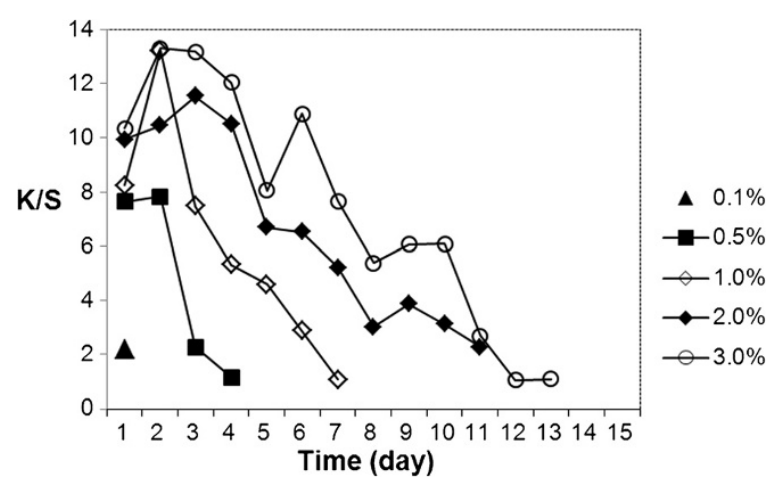

Figure 4 Time-based changes in $\mathrm{K} / \mathrm{S}$ values depending on the extract concentration.

Figure 3 shows the stability of indigo reduction vat depending on the extract concentration. The reducing power of indigo vat was maintained at $-550 \sim-600 \mathrm{mV}$ for longer time at higher concentration of the extract. At $0.1 \%$, reduction maintained for only one day as indicated by the change in reduction potential from $-560 \mathrm{mV}$ to $-30 \mathrm{mV}$. At $3.0 \%$ of the Bokbunja sludge extract concentration, reduction potential stabilized at below $-550 \mathrm{mV}$ was maintained for 13 days while remianed for 11 days at $2.0 \%$. This indicates that the indigo vat stabilized at $-550 \sim-600 \mathrm{mV}$ can be used repeatedly as long as it maintains reducing power. In the case of sodium dithionite $(0.45 \mathrm{~g} \sim 1.0 \mathrm{~g} / \mathrm{l})$, the reduction potential generated was stabilized at $-550 \sim-600 \mathrm{mV}$ (data not shown). It was considered that the reducing power of the Bokbunja sludge extract was comparable to sodium dithionite. In addition, considering that the requisite reduction potential of indigo lies approximately $-600 \mathrm{mV}$ (Bozic and Kokol, 2008), the Bokbunja sludge extract can be an alternative choice to sodium dithionite as a reducing agent in indigo dyeing processes.

\section{Color yield}

The reaction medium obtained resulted from the reduction process was used as a dyebath at $60^{\circ} \mathrm{C}$. The quality of dyeing was evaluated at different concentration by measuring the color yield parameter (K/S value). The results are presented in Figure 4. At $0.1 \%$ of the extract, $\mathrm{K} / \mathrm{S}$ value was 2.18 and this level of concentration was considered to be too low to give sufficient reducing power. All curves have basically the same shape irrespective of the extract concentration. They are composed of two parts. In the first part within one or two days, it is noted a sharp increasing of color yield which attained maximum K/S values about 7.83, 13.22, 11.55 and 13.30 at 0.5, 1.0, 2.0 and $3.0 \%$ of the extract, respectively. In the second part of the curves, a rapid decreasing of the color yield as time extended. It was considered that reduction potential should be evolved at least $-550 \mathrm{mV}$ for triggering reduction reaction and attaining color yield.

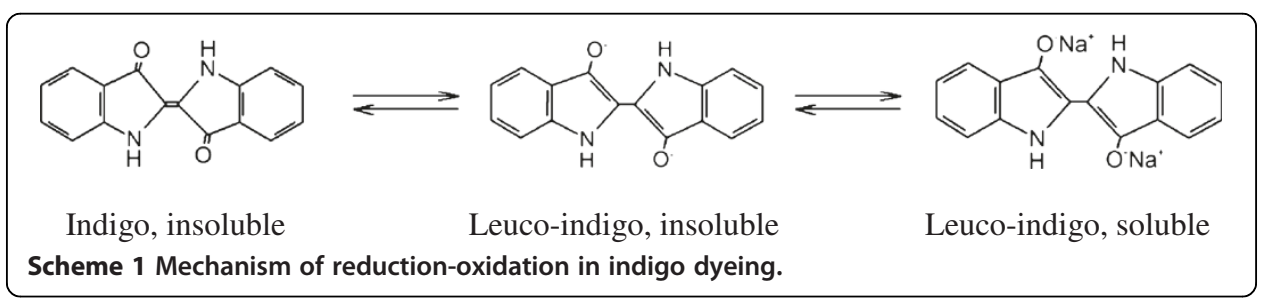


From the results of reduction potential and color yield measurements, it was confirmed that the Bokbunja sludge extract could be an eco-friendly and safe alternative to sodium dithionite as a reducing agent in indigo dyeing processes.

\section{Reduction mechanism of indigo using the extract}

Indigo has extremely low solubility in water, dilute acids and dilute alkalis due to intraand inter-molecular hydrogen bonding (Vuorema, et al., 2009). Indigo is readily reduced by various reagents, such as sodium dithionite. If we consider the reduction of indigo by the studied reductant, i.e., the Bokbunja sludge extract, two reactions could be involved. First, the oxidation reaction of reducing sugars in the Bokbunja sludge extract may occur to provide electrons to indigo (Meksi et al., 2012). Secondly, the reduction of indigo occurs to accept two electrons from reducing sugar. So, blue indigo transformed to colorless and partially soluble leuco-indigo. At a high alkaline medium $(\mathrm{pH} 11)$, the yellowish brown, soluble sodium salt of leuco-indigo is formed to be able to penetrate into fiber. The sodium salt of leuco-indigo can be transformed by acids to leuco-indigo which is colorless. The mechanism of reduction-oxidation in indigo dyeing is presented in Scheme 1. The reduced indigo dyes are converted back to the insoluble indigo by the oxidation reaction. Finally, blue color appears on the fabric by the oxidation reaction as exposed to atmospheric oxygen. The aggregate of indigo dye molecule becomes trapped mechanically within the fiber.

\section{Conclusion}

The utilization of Bokbunja (Rubus coreanus) sludge as a source of reductant was investigated to develop an eco-friendly indigo dyeing process. The water extract showed relatively high DPPH radical scavenging activity and contained high sugar content of $50.87 \%$. The extract was effective to reduce indigo dye. The reduction of indigo was occured with the Bokbunja sludge extract rapidly at $80^{\circ} \mathrm{C}$ and the maximum color yield was reached in one or two days. The reduction potential of the extract was stabilized at about $-550 \sim-600 \mathrm{mV}$ depending on concentration of the extract. At higher concentration of the extract, reduction lasted for longer time and higher color yield was obtained. It was confirmed that the Bokbunja sludge extract could be an eco-friendly and safe alternative to sodium dithionite as a reducing agent in indigo dyeing processes.

Competing interests

The authors declare that they have no competing interests.

Authors' contributions

MC carried out experiments on analysis and reduction studies. YS and DIY participated in the sequence alignment and drafted the manuscript. All authors read and approved the final manuscript.

\section{Acknowledgements}

This work was supported by the National Research Foundation of Korea (NRF) grant funded by the Korea government (MSIP) (No. 2013029705).

\section{Author details}

${ }^{1}$ Department of Clothing and Textiles/Human Ecology Research Institute, Chonnam National University, Gwangju,

Korea. ${ }^{2}$ Department of Polymer and Fiber System Engineering, Chonnam National University, Gwangju, Korea.

Received: 18 January 2014 Accepted: 17 March 2014

Published online: 08 July 2014

References

Arnao, MB. (2000). Some methodological problems in the determination of antioxidant activity using chromogen radicals: a practical case. Trends Food Science and Technology, 11, 419-421. 
Blackburn, RS, \& Harvey, A. (2004). Green chemistry methods in sulfur dyeing: application of various reducing D-sugars and analysis of the importance of optimum redox potential. Environmental Science \& Technology, 38, 4034-4039. Blois, MS. (1958). Antioxidant determinations by the use of a stable free radical. Nature, 181, 1199-1200.

Bozic, M, \& Kokol, V. (2008). Ecological alternatives to the reduction and oxidation processes in dyeing with vat and sulphur dyes. Dyes and Pigments, 76, 299-309.

Choi, HS, Kim, MK, Park, HS, Kim, YS, \& Shin, DH. (2006). Alcoholic fermentation of bokbunja (Rubus coreanus Miq.) wine. Korean Journal of Food Science and Technology, 38, 543-547.

Eiro, MJ, \& Heinonen, M. (2002). Anthocyanin color behavior and stability during storage: effect of intermolecular copigmentation. Journal of Agricultural and Food Chemistry, 50, 7461-7466.

$\mathrm{Ku}, \mathrm{CS}$, \& Mun, SP. (2008). Characterization of seed oils from fresh bokbunja (Rubus coreanus Miq.) and wine processing waste. Bioresource Technolology, 99, 2852-2856.

Masukoa, T, Minamib, A, Iwasakib, N, Majimab, T, Nishimura, S-I, \& Leea, YC. (2005). Carbohydrate analysis by a phenol-sulfuric acid method in microplate format. Anaytical Biochemistry, 339, 69-72.

Meksi, N, Ticha, MB, Kechida, M, \& Mhenni, MF. (2012). Using of ecofriendly a-hydroxycarbonyls as reducing agents to replace sodium dithionite in indigo dyeing processes. Journal of Cleaner Production, 24, 149-158.

Moure, A, Cruz, JM, Franco, D, Domı'nguez, JM, Sineiro, J, Domínguez, H, \& Nu'ñez, MJ. (2001). Natural antioxidants from residual sources. Food Chemistry, 72, 145-171

Peschel, W, Sa'nchez-Rabaneda, F, Diekmann, W, Plescher, A, Gartz'a, I, Jime'nez, D, Lamuela-Ravento's, R, Buxaderas, S, \& Codina, C. (2006). An industrial approach in the search of natural antioxidants from vegetable and fruit wastes. Food Chemistry, 97, 137-150.

Saha, AK, \& Brewer, CF. (1994). Determination of the concentrations of oligosaccharides, complex type carbohydrates, and glycoproteins using the phenol-sulfuric acid method. Carbohydrate Research, 254, 157-167.

Vareed, SK, Reddy, MK, Schutzki, RE, \& Nair, MG. (2006). Anthocyanins in cornus alternif olia, cornus controversa, cornus kousa and cornus florida fruits with health benefits. Life Science, 78, 777-784.

Vuorema, A, John, P, Keskitalo, M, Mahon, MF, Kulandainathand, MA, \& Marken, F. (2009). Anthraquinone catalysis in the glucose-driven reduction of indigo to leuco-indigo. Physical Chemistry Chemical Physics, 11, 1816-1824.

Yoon, I, Wee, JH, Moon, JH, Ahn, TH, \& Park, KH. (2003). Isolation and identification of quercetin with antioxidative activity from the fruits of rubus coreanum Miquel. Korean Journal of Food Science and Technology, 35, 499-502.

doi:10.1186/s40691-014-0006-5

Cite this article as: Shin et al.: Eco-friendly indigo reduction using bokbunja (Rubus coreanus Miq.) sludge.

Fashion and Textiles 2014 1:6.

\section{Submit your manuscript to a SpringerOpen ${ }^{\circ}$} journal and benefit from:

- Convenient online submission

- Rigorous peer review

- Immediate publication on acceptance

- Open access: articles freely available online

- High visibility within the field

- Retaining the copyright to your article

Submit your next manuscript at $\boldsymbol{\sim}$ springeropen.com 